\title{
Analisis Strategi Promosi Kesehatan dalam Rangka Meningkatkan Kesadaran Hidup Sehat oleh Rumah Sakit Jiwa Daerah Dr. RM. Soedjarwadi Provinsi Jawa Tengah
}

\author{
Ratih Gayatri Setyabudi \\ Prodi Ilmu Komunikasi Universitas Islam Indonesia, Yogyakarta \\ Mutia Dewi \\ Prodi Ilmu Komunikasi Universitas Islam Indonesia, Yogyakarta
}

\begin{abstract}
Abstrak
Penelitian ini dilakukan di Dr. RM. Rumah Sakit Soedjarwadi, Provinsi Jawa Tengah, sebagai salah satu rumah sakit jiwa yang melayani penderita penyakit jiwa. Penelitian ini menggunakan pendekatan kualitatif dengan metode studi kasus. Metode pengumpulan data yang digunakan dalam penelitian ini adalah observasi, wawancara, dokumentasi dan pelacakan data secara online. Studi ini menemukan bahwa tim PKRS daerah Rumah Sakit Jiwa Dr. RM. Soeedjarwadi Provinsi Jawa Tengah menerapkan strategi promosi kesehatan. Pertama, advokasi berupa lobi politik, seminar dan/atau presentasi dan advokasi media. Kedua, dukungan sosial (Social Support) dimana strategi tersebut disebut sebagai pengembangan atmosfir atau menumbuhkan suasana yang kondusif. Pendirian atmosfer ini terbagi menjadi tiga bentuk, yaitu perkembangan atmosfir individu, pengembangan atmosfir masyarakat dan suasana masyarakat. Ketiga, pemberdayaan masyarakat (Empowerment Community) yang merupakan proses pemberian informasi kepada kelompok, keluarga dan invidu secara terus menerus. Dengan strategi promosi kesehatan, akan membantu pihak rumah sakit dalam mewujudkan dan meningkatkan kesadaran akan kesehatan dalam kehidupan masyarakat.
\end{abstract}

Kata Kunci: Komunikasi Kesehatan, aktivitas promosi kesehatan, strategi

\begin{abstract}
Data collection that used in this study are observation, interviews, documentation and online data tracking. This study found that PKRS team of region Mental Hospital Dr. RM. Soeedjarwadi Central Java Province implements health promotion strategies. First from advocacy in the form of political lobbying, seminars and/or presentations and media advocacy. Second, social support (Social Support) where the strategy is referred to as the development of atmosphere or foster a conducive atmosphere. Establishment of this atmosphere is divided into three forms, the development of individual atmosphere, community atmosphere development and public atmosphere building. Third, empowerment community (Empowerment Community) which is the process of providing information to the group, family and invidu continuously. With the health promotion strategy, it will help the hospital in realizing and increasing awareness of health in the life of the community.
\end{abstract}

Keywords: Health Communication, Health Promotion Activity, Strategy 


\section{Pendahuluan}

Komunikasi merupakan hal penting dalam kehidupan manusia. Manusia adalah makhluk sosial sehingga dalam aktivitasnya memerlukan komunikasi antara satu dengan lainnya. Menurut Lauwrence D. Kincaid, komunikasi adalah proses di mana dua orang atau lebih melakukan pertukaran informasi dengan satu sama lainnya, yang pada gilirannya akan mendapatkan feedback (Cangara, 2014: 36). Dengan demikian, komunikasi menjadi salah satu unsur yang penting didalam kehidupan manusia.

Salah satu komunikasi yang sangat penting dalam kehidupan manusia adalah komunikasi kesehatan. Menurut UndangUndang Kesehatan No.23 tahun 1992, kesehatan adalah keadaan sejahterah badan, jiwa, dan sosial yang memungkinkan setiap orang hidup produktif secara sosial dan ekonomi. Kesehatan ini mencakup 4 aspek, yakni fisik (badan), mental (jiwa), sosial, dan ekonomi (Notoatmodjo, 2007: 3). Pentingnya kesehatan sangat dirasakan oleh sebagian besar manusia. Bahkan, ada kalimat yang menyatakan bahwa "Kesehatan itu sangat mahal". Kalimat tersebut memperjelas bahwa hidup dalam keadan fisik serta mental yang sehat memang sangatlah penting. Dengan fisik dan jiwa yang sehat, seseorang dapat melakukan aktivitasnya sehari-hari. Salah satu sarana pelayanan yang digunakan untuk penyembuhan fisik maupun jiwa adalah rumah sakit. Menurut UU RI Nomor 44 tahun 2009 tentang rumah sakit, rumah sakit adalah sebuah institusi pelayanan kesehatan yang menyelenggarakan pelayanan kesehatan perorangan secara menyeluruh yang menyediakan pelayanan rawat inap, rawat jalan, dan gawat darurat (Direktorat Jenderal Pendidikan Tinggi, 2009).

Rumah sakit memiliki perbedaan kelas, fungsi dan juga peranan masingmasing. Rumah sakit jiwa memiliki tujuan mencegah adanya gangguan jiwa pada masyarakat (promosi preventif), menyembuhkan pasien dengan gangguan jiwa dengan cara penyembuhan yang optimal, dan rehabilitasi bidang kesehatan jiwa (Nugroho, 2003). Rumah sakit jiwa merupakan salah satu contoh rumah sakit yang memiliki kewajiban untuk meningkatkan kesehatan bagi masyarakat, terutama masyarakat yang memiliki masalah pada kejiwaannya. Namun, saat ini, beberapa rumah sakit jiwa tidak hanya memberikan pengobatan untuk pasien dengan masalah kejiwaannya saja, tetapi juga menangani pasien dengan penyakit non jiwa.

Komunikasi kesehatan diperlukan di rumah sakit jiwa sebagai salah satu kegiatan untuk meningkatkan kesadaran 
akan hidup sehat, baik jasmani maupun rohani. Tujuan komunikasi kesehatan itu sendiri adalah sebagai sarana penyampaian informasi atau pesan mengenai kesehatan kepada masyarakat. Komunikasi kesehatan secara praktis memberikan kontribusi untuk promosi kesehatan, dan mencegah penyakit dalam suatu wilayah tertentu. Dengan adanya promosi kesehatan, akan membantu masyarakat untuk mengetahui berbagai hal mengenai informasi atau pesan-pesan kesehatan yang ada, masalah kesehatan serta penanganan masalah kesehatan baik fisik maupun non fisik.

Untuk mencapai sasaran dalam promosi kesehatan, diperlukan strategi sebelum menjalankan promosi kesehatan. Strategi promosi kesehatan tersebut terdiri dari advokasi, dukungan sosial, dan juga pemberdayaan masyarakat. Baik rumah sakit umum maupun rumah sakit jiwa perlu adanya promosi kesehatan dengan ketiga strategi tersebut supaya masyarakat dapat menanamkan rasa kesadaran pada diri mereka sendiri akan hidup bersih dan sehat.

Rumah Sakit Jiwa Daerah Dr. RM. Soedjarwadi mempunyai berbagai kegiatan yang menunjang penyampaian informasi kesehatan, baik untuk pasien jiwa dan non jiwa ataupun juga masyarakat. Salah satunya yang dilakukan baru-baru ini adalah penyuluhan mengenai kesehatan jiwa yang ditujukan kepada pasien maupun keluarga pasien. Penyuluhan disampaikan oleh dr. Eni Kusumawati, Sp. KJ. M. Kes di
Poli Jiwa RSJD Dr. RM. Soedjarwadi. Penyuluhan menekankan peranan keluarga pasien dalam mempercepat proses penyembuhan. Selain itu, kedisiplinan dalam minum obat juga menjadi salah satu topik penting (www.rsjd-sujarwadi.jatengprov.go.id).

Rumah sakit sebagai salah satu sarana dan prasarana untuk membantu masyarakat dalam masa penyembuhan, memerlukan dukungan promosi kesehatan yang dilakukan melalui strategi advokasi, dukungan sosial, dan pemberdayaan masyarakat. Ini karena dengan adanya promosi kesehatan akan membantu meningkatkan kesadaran masyarakat akan pentingnya hidup sehat, baik hidup sehat secara fisik maupun mental. Penjelasan tersebut menjadi alasan penulis untuk mengetahui strategi promosi kesehatann yang dilakukan oleh Rumah Sakit Jiwa Daerah Dr. RM. Soedjarwadi dalam rangka meningkatkan kesadaran hidup sehat. Kemudian, faktor-faktor apa saja yang menjadi pendukung dan penghambat dalam melakukan strategi promosi kesehatan di Rumah Sakit Jiwa Daerah Dr. RM. Soedjarwadi?

Komunikasi memiliki pengertian yang berbeda sesuai dengan bidang-bidang yang ada. Salah satunya adalah komunikasi kesehatan. Dalam kaitannya antara komunikasi dalam bidang kesehatan, berfungsi sebagai peningkatan yang dibutuhkan suatu elemen dalam upaya meningkatkan kesetaraan dalam kesehatan individu dan masyarakat. 
Komponen komunikasi kesehatan meliputi komunikator, pesan, dan komunikan.

Definisi komunikasi kesehatan adalah studi yang mempelajari bagaimana cara menggunakan strategi komunikasi dalam menyebarluaskan informasi atau pesan kesehatan yang dapat mempengaruhi individu dan komunitas agar mereka dapat membuat keputusan yang tepat berhubungan dengan pemeliharaan kesehatan (Liliweri, 2007: 46).

Salah satu bentuk informasi komunikasi kesehatan yang ditujukan untuk masyarakat adalah promosi kesehatan. Promosi kesehatan bukan hanya sebagai proses penyadaran komunitas yang ada di masyarakat ataupun individu pemberian dan peningkatan pengetahuan dalam bidang kesehatan saja, tetapi juga merupakan sebuah program kesehatan yang telah dirancang untuk memperbaiki perubahan perilaku, baik dalam masyarakat maupun organisasi. Promosi kesehatan dapat dilakukan dengan metode dan media, sebagai berikut.

\section{a. Metode Promosi Kesehatan}

Secara garis besar, metode promosi kesehatan dibagi menjadi dua, yaitu sebagai berikut.

1. Metode Didaktif

Metode didaktif ini didasarkan atau dilakukan dengan cara satu arah. Tingkat keberhasilan dari metode didaktif ini sulit untuk dievaluasi karena peserta didik bersifat pasif dan hanya pendidik yang aktif. Misalnya: ceramah, film, leaflet, booklet, poster, dan siaran radio.

2. Metode Sokratif

Metode sokratif ini dilakukan dengan cara dua arah. Dengan menggunakan metode ini, kemungkinan antara pendidik dan peserta didik bersikap aktif dan kreatif. Misalnya: diskusi kelompok, debat, panel, forum, seminar, bermain peran, curah pendapat, demonstrasi, studi kasus, lokakarya, dan penugasan perorangan.

Selain itu, metode promosi kesehatan berdasarkan teknik komunikasi, yaitu dibagi sebagai berikut.

1. Metode Penyuluhan Langsung

Dalam metode penyuluhan langsung para penyuluh langsung berhadapan atau bertatap muka dengan sasaran. Termasuk disini antara lain adalah kunjungan rumah.

2. Metode Penyuluhan Tidak Langsung Dalam metode penyuluhan tidak langsung, para penyuluh atau komunikator kesehatan tidak berhadapan atau bertatap muka secara langsung dengan komunikan. Tetapi komunikator menggunakan media sebagai perantara dalam penyampaian pesan. Misalnya: publikasi dalam bentuk media cetak (Wardani, Muyassaroh dan Ani, 2016: 9-10). 

Kesadaran Hidup Sehat oleh Rumah Sakit Jiwa Daerah Dr. RM. Soedjarwadi Provinsi Jawa Tengah

b. Media Promosi Kesehatan

Media promosi kesehatan merupakam sarana atau upaya dalam menampilkan pesan atau informasi yang ingin disampaikan oleh komunikator kepada komunikan, baik itu melalui media cetak, elektronik (TV, radio, komputer dan lainlain) dan media luar ruang sehingga target sasaran yang dituju dapat meningkatkan pengetahuannya dan diharapkan dapat berubah perilaku kesehatannya ke arah yang positif (Depkes RI, 2006).

Selain media yang disebutkan sebelumnya, seiring dengan perkembangan zaman dan teknologi, munculah media sosial. Media sosial merupakan salah satu media yang dapat mempermudah masyarakat dalam mendapatkan informasi mengenai berbagai hal. Ini media sosial merupakan media yang sangat mudah untuk diakses. Beberapa media sosial yang telah dikenal adalah twitter, facebook, website, e-mail, instagram, dan masih banyak yang lainnya.

Salah satu upaya untuk meningkatkan kemampuan pasien, klien, dan kelompok masyarakat dalam rangka mempercepat proses penyembuhan, meningkatkan kesehatan, mencegah masalah kesehatan, dan mengembangkan upaya kesehatan adalah promosi kesehatan di rumah sakit. Johnson dan Baum menyebutkan bahwa jaringan dalam promosi kesehatan di rumah sakit terdiri dari empat komponen, yaitu pasien, staf, keluarga dan organisasi. (Alhamda, Jurnal
Manajemen Pelayanan Kesehatan, Vol. 15 No. 02, Juni 2012: 77-85). Di Indonesia, promosi kesehatan mempunyai visi dan misi berdasarkan Surat Keputusan Menteri Kesehatan Republik Indonesia Nomor 1193/2004 mengenai Kebijakan Nasional Promosi Kesehatan.

Dalam menjalankan promosi kesehatan, pihak Rumah Sakit juga harus menentukan sasaran dari kegiatan promosi kesehatan tersebut.Adapun sasaran dari promosi kesehatan dibagi menjadi 3 (tiga), yaitu sebagai berikut.

1. Sasaran Primer

Sasaran primer merupakan kelompok masyarakat yang nantinya akan diubah perilakunya. Dalam praktik promosi kesehatan, sasaran primer ini dibagi menjadi beberapa kelompok, yaitu kepala keluarga, ibu hamil, ibu menyusui, ibu anak balita, anak sekolah, remaja, pekerja di tempat kerja, masyarakat yang berada di tempattempat umum, dan lain sebagainya.

2. Sasaran Sekunder

Sasaran sekunder yang dimaksud adalah tokoh masyarakat baik formal maupun informal.

\section{Sasaran Tertier}

Masyarakat memerlukan faktor pemungkin (enabling) untuk berperilaku sehat, yaitu dengan adanya sarana dan prasarana demi mewujudkan perilaku tersebut. Misalnya lurah, camat, bupati, atau pejabat pemerintah setempat. Oleh 
karenanya, kegiatan promosi kesehatan dapat menjadikan para pejabat sebagai sasaran tertier (Kholid, 2012: 15-16).

Menurut Wahyono (2013), dalam perencanaan Promosi Kesehatan Rumah Sakit (PKRS), meliputi kelompok perencana, mengidentifikasi hambatan serta sumber daya, menetapkan tujuan, mengidentifikasi metode, kegiatan dan tujuan program, serta rencana implementasi dna evaluasi. Adapun tujuan akhirnya adalah untuk peningkatan kesetaraan kesehatan masyarakat secara mandiri.

Promosi kesehatan bertujuan agar tersosialisasinya program-program kesehatan demi terwujudnya masyarakat Indonesia baru yang berbudaya dengan hidup bersih dan juga sehat serta berpartisipasi secara langsung dalam gerakan kesehatan. Untuk mencapai tujuan dalam mewujudkan promosi kesehatan, diperlukan sebuah strategi yang baik. Strategi adalah cara dalam mencapai maupun mewujudkan visi dan misi kesehatan secara efektif dan efisien (Wardani, Muyassaroh dan Ani, 2016: 137).

Mubarak dan Chayatin (2008) menyebutkan bahwa strategi yang diperlukan untuk mewujudkan promosi kesehatan adalah sebagai berikut.
1. Advokasi

Advokasi merupakan kegiatan yang memberikan bantuan kesehatan kepada masyarakat melalui pihak pembuat keputusan dan penentu kebijakan dalam bidang kesehatan. Advokasi merupakan upaya atau sebuah proses yang strategis dan terencana dengan tujuan mendapatkan komitmen dan dukungan dari pihak-pihak yang terkait (stakeholders). Tujuan advokasi kesehatan ini adalah untuk meningkatkan jumlah kebijakan publik berwawasan kesehatan, untuk meningkatkan opini masyarakat dalam mendukung kesehatan, dan terpecahkannya masalah kesehatan secara bersama dan terintegrasi dengan pembangunan kesehatan didaerah melalui kemitraan dan adanya dukungan serta kepedulian dari pimpinan daerah (Solang, Losu dan Tando, 2016: 72). Sasaran advokasi kesehatan adalah para pengambil keputusan dan juga kebijakan baik dalam tingkat propinsi, kota atau kabupaten, dan juga pusat. Untuk kegiatan advokasi kesehatan, terdiri dari berbagai macam bentuk, baik formal maupun informal

Bentuk kegiatan advokasi dapat dilakukan dengan beberapa cara antara lain sebagai berikut.

- Lobi Politik (Political Lobbying) Lobi adalah berbincang-bincang secara informal dengan para petinggi atau pejabat untuk menginformasikan serta membahas masalah dan juga program kesehatan yang akan 

Kesadaran Hidup Sehat oleh Rumah Sakit Jiwa Daerah Dr. RM. Soedjarwadi Provinsi Jawa Tengah

dilaksanakan. Pada saat melaksanakan lobi, harus disertai dengan data yang akurat dan sesuai dengan fakta yang ada mengenai masalah kesehatan tersebut.

- Seminar dan atau Presentasi

Seminar ataupun presentasi menampilkan masalah kesehatan di depan para pembuat keputusan baik lintas program maupun lintas sektoral. Penyajian mengenai masalah kesehatan disajikan secara lengkap didukung dengan data dan ilustrasi yang menarik, serta program dan solusi dalam pemecahan masalah kesehatan yang ada. Selanjutnya masalah tersebut dibahas secara bersamasama dan akhirnya akan diperoleh komitmen dan dukungan program yang akan dilaksanakan.

- Media Advokasi

Media advokasi merupakan kegiatan advokasi yang dilakukan dengan menggunakan media, khususnya penggunaan media massa (media cetak dan media elektronik).

- Perkumpulan (Asosiasi) Peminat Asosiasi atau perkumpulan orangorang yang memiliki minat atau yang berhubungan dengan masalah tertentu, termasuk juga perkumpulan profesi.
2. Dukungan Sosial (Social Support)

Promosi kesehatan akan mudah dilakukan apabila mendapatkan dukungan sosial. Dukungan sosial adalah sebuah kegiatan dengan tujuan untuk mencari dukungan dari berbagai elemen (tokohtokoh masyarakat) untuk menjembatani antara pelaksana program kesehatan dengan masyarakat sebagai penerima program kesehatan tersebut. Strategi ini dapat disebut sebagai upaya bina suasana atau membina suasana yang kondusif terhadap kesehatan. Sasaran utama dukungan sosial atau bina suasana ini adalah para tokoh masyarakat di berbagai tingkat (sasaran sekunder), sedangkan untuk sasaran dukungan sosial atau bina suasana lainnya terdiri dari kelompok peduli kesehatan, para pemuka agama, tenaga profesional kesehatan, institusi pelayanan kesehatan, organisasi massa, tokoh masyarakat, kelompok media massa, dan lembaga swadaya masyarakat.

Adapun bentuk-bentuk dukungan sosial yang dilaksanakan di masyarakat diantaranya sebagai berikut.

- Bina Suasana Individu Bina suasana individu ini dilakukan oleh individu tokoh-tokoh masyarakat. Para tokoh masyarakat ini menjadi individu-individu yang menjadi panutan dalam hal mempraktikan program kesehatan yang sedang diperkenalkan. 
- Bina Suasana Kelompok Bina suasana kelompok dilakukan oleh para kelompok-kelompok yang ada didalam masyarakat, seperti ketua RT, RW, karang taruna, serikat pekerja dan lain sebagainya. Dalam hal ini, kelompok-kelompok tersebut menjadi kelompok yang peduli dengan program kesehatan yang sedang diperkenalkan dan setuju atas program kesehatan tersebut serta mendukung program kesehatan tersebut.

- Bina Suasana Publik

Bina suasana publik dilakukan oleh masyarakat umum melalui pemanfaatan media-media komunikasi yang ada. Sebagai contoh radio, TV, koran, majalah, websites, dan lain sebagainya. Dalam hal ini, media massa yang ada peduli serta menjadi pendukung dalam program kesehatan yang sedang diberlakukan atau diperkenalkan (Solang, Losu dan Tando, 2016: 6668).

3. Pemberdayaan Masyarakat (Empowerment Community)

Pemberdayaan masyarakat merupakan upaya promosi kesehatan. Pemberdayaan ialah sebuah proses pemberian informasi kepada keluarga atau kelompok dan individu secara terus menerus dan berkesinambungan dengan mengikuti perkembangan masyarakat, serta proses membantu masyarakat supaya masyarakat berubah dari yang awalnya tidak tahu menjadi tahu atau sadar serta dari tahu menjadi mau dan dari mau menjadi mampu untuk melaksanakan program kesehatan yang diperkenalkan (Solang, Losu dan Tando, 2016: 59-64). Ada dua tujuan promosi kesehatan yang dihubungkan dengan pembedaryaan masyarakat. Pertama, pemberdayaan merupakan sebuah cara dimana masyarakat diarahkan mampu untuk melaksanakan kehidupannya. Kedua, dapat meningkatkan perilaku hidup sehat di masyarakat dan ketiga yaitu dapat meningkatkan peran masyarakat dalam upaya kesehatan.

Analisis SWOT merupakan instrumen perencanaan yang dapat digunakan untuk mengukur kekuatankekuatan yang dimiliki (strengths) kemudian kelemahan-kelemahan yang ada (weakness), juga peluang-peluang yang mungkin dapat diperoleh (opportunities) dan ancaman yang dapat ditemui (threats) (Cangara, 2014: 106). Analisis SWOT didasarkan pada logika yang dapat memaksimalkan empat elemen dalam perencanaan tersebut. Proses pengambilan strategi dan keputusan perusahaan pada umumnya berkaitan dengan pengembangan visi misi, tujuan, strategi serta kebijakan perusahaan. Oleh karena itu, perencanaan strategi harus menganalisa elemen-elemen yang ada dalam analisis ini yaitu, kekuatan, 
kelemahan, peluang dan ancaman dalam kondisi yang ada.

Terdapat dua faktor yang mempengaruhi SWOT, yaitu faktor internal dan eksternal. Faktor internal menyangkut tentang apa yang terjadi atau kondisi di dalam suatu organisasi atau perusahaan, faktor internal meliputi semua manajemen fungsional yang ada dalam organisasi tersebut. Faktor internal ini berupa kekuatan (strengths) dan kelemahan (weakness) sedangkan faktor eksternal menyangkut apa yang terjadi atau kondisi diluar suatu organisasi atau perusahaan, faktor eksternal mencakup lingkungan industri, bisnis, sosial, budaya, hukum, kependudukan dan teknologi. Faktor eksternal ini berupa peluang (opportunities) dan ancaman (threats).

\section{Metode Penelitian}

Penelitian ini menggunakan pendekatan kualitatif. Bogdan dan Taylor (Moleong, 2002: 3) mendefinisikan penelitian kualitatif sebagai penelitian yang menghasilkan data deskriptif berupa kata-kata tertulis atau secara lisan dari orang atau perilaku yang dapat diamati. Definisi ini memfokuskan pada jenis data yang dikumpulkan dalam penelitian, yaitu data deskriptif kualitatif. Penelitian kualitatif merupakan penelitian yang menghasilkan data deskriptif dan berupaya menggali makna dari suatu fenomena atau isu yang sedang terjadi atau telah terjadi (M. Djamal. 2015: 9). Metode penelitian deskriptif dengan menggunakan pendekatan kualitatif bertujuan untuk mendapatkan sebuah pemahaman terhadap suatu realitas sosial dari perspektif partisipan.

Penelitian ini dilakukan pada bulan Februari 2017 di Rumah Sakit Jiwa Daerah Dr. RM. Soedjarwadi Provinsi Jawa Tengah sebagai proses pencarian dan pengambilan data yang diperlukan penulis dalam penelitian ini. Narasumber dipilih berdasarkan purposive sampling, yakni teknik penentuan sampel dengan pertimbangan tertentu. Narasumber yang dimaksud adalah Kepala PKRS (Promosi Kesehatan Rumah Sakit) Rumah Sakit Jiwa Daerah Dr. RM. Soedjarwadi, satu karyawan Unit Pengaduan Rumah Sakit jiwa Daerah Dr. RM. Soedjarwadi dan dua keluarga pasien rawat inap Rumah Sakit jiwa Daerah Dr. RM. Soedjarwadi.

\section{Analisis dan Pembahasan}

\section{Analisis Metode Promosi Kesehatan dalam Rangka Meningkatkan Kesadaran Hidup Sehat}

Promosi kesehatan termasuk ke dalam komunikasi kesehatan dimana dalam komunikasi antar manusia memiliki fokus mengenai bagaimana seorang individu dalam suatu kelompok/masyarakat dalam menghadapi isu-isu yang berkaitan dengan kesehatan dan berupaya dalam menjaga kesehatannya (Northouse dalam Notoatmodjo, 2005). Komunikasi 
kesehatan memiliki sistem komunikasi yang dapat mendukung dalam penyampaian akan informasi mengenai promosi kesehatan. Sistem komunikasi yang dilakukan oleh pihak RSJD Dr. RM. Soedjarwadi baik untuk perorangan maupun keseluruhan (atasan dengan bawahan). Salah satu bentuk informasi yang termasuk didalam komunikasi kesehatan adalah promosi kesehatan.

Sebagai rumah sakit jiwa daerah yang telah terakreditasi A, RSJD Dr. RM. Soedjarwadi Provinsi Jawa Tengah telah melakukan kegiatan-kegiatan promosi kesehatan baik untuk pasien jiwa maupun pasien non jiwa dengan menggunakan beberapa metode dari promosi kesehatan. Promosi kesehatan adalah upaya dalam meningkatkan kemampuan masyarakat melalui proses pembelajaran dari, oleh, untuk, dan bersama masyarakat. Supaya masyarakat dapat menolong dirinya sendiri dan mengembangkan kegiatan yang bersumber daya masyarakat, sesuai dengan kondisi sosial budaya setempat dan didukung dengan kebijakan publik yang berwawasan kesehatan (Pamsimas, 2009).

Penerapan promosi kesehatan di lapangan biasanya melalui pendidikan kesehatan dan penyuluhan kesehatan (Kholid, 2012: 67). Kegiatan-kegiatan dengan menggunakan metode promosi kesehatan yang dilakukan oleh RSJD Dr. RM. Soedjarwadi Provinsi Jawa Tengah adalah sebagai berikut.

\section{a.Metode Promosi Kesehatan Jiwa}

RSJD Dr. RM. Soedjarwadi menggunakan metode didaktif dalam promosi kesehatan jiwa baik secara langsung maupun tidak langsung dengan menetapkan sasaran-sasaran yang akan dituju. Sasaran-sasaran tersebut adalah sasaran primer, sekunder, dan tertier. RSJD Dr. RM. Soedjarwadi menggunakan media cetak, media luar ruang, media elektronik dan media sosial sesuai dengan karakteristik dan pemanfaatan media dalam hal promosi kesehatan dan telah disesuaikan dengan target sasarannya. Teknik komunikasi secara langsung maupun tidak langsung dengan menggunakan media cetak, media elektronik, media luar ruang dan media sosial telah disesuaikan oleh RSJD Dr. RM. Soedjarwadi sesuai dengan sasaran yang akan dituju. Karena hal tersebut akan membantu pasien, keluarga pasien, pegawai RSJD dan para stakeholders RSJD dalam meningkatkan kesadaran kesehatan jiwanya baik secara langsung maupun tidak langsung.

Kegiatan promosi kesehatan jiwa RSJD Dr. RM. Soedjarwadi didukung oleh tim IPKRS yang menggunakan metode sokratif, yaitu metode yang dilakukan dengan dua arah (Wardani, Muyasaroh dan Ani, 2016: 9). Metode sokratif yang digunakan oleh rumah sakit baik secara langsung maupun tidak langsung 
berhasil mencapai target sasaran yang telah ditentukan. Seperti sasaran primer dengan melibatkan pasien jiwa baik dari anak-anak, remaja maupun dewasa selanjutnya keluarga pasien jiwa rawat inap dan rawat jalan dan para pegawai di lingkungan rumah sakit. Kemudian, sasaran sekunder seperti kepala desa dan para tokoh masyarakat desa yang dapat bekerjasama dengan rumah sakit dalam mempromosikan kesehatan jiwa di daerah-daerah perdesaan dengan kepala desa dan tokoh masyarakat yang menjadi jembatan antara masyarakat dan IPKRS rumah sakit. Terakhir adalah sasaran tertier dimana terdiri dari para dokter dan psikolog rumah sakit, LSM bidang kesehatan jiwa, stakeholders rumah sakit, lurah, bupati dan lain sebagainya yang turut berpartisipasi dalam mempromosikan kesehatan baik secara langsung maupun tidak langsung. Selanjutnya, dalam teknik komunikasi secara langsung dan tidak langsung dengan menggunakan media massa, dirasa telah tepat dalam pemanfaatannya berdasarkan sasaransasaran yang dituju oleh rumah sakit. Dengan menggunakan media cetak, luar ruang, elektronik dan juga sosial akan mampu membantu rumah sakit dalam mepromosikan kesehatan kepada masyarakat. Walaupun ada beberapa kegiatan promosi kesehatan yang tidak menggunakan media elektronik dan sosial karena telah ditentukan berdasarkan sasaran yang ditetapkan oleh rumah sakit.

\section{b.Analisis Metode Promosi Kesehatan Non Jiwa}

RSJD Dr. RM. Soedjarwadi menggunakan metode didaktif dalam promosi kesehatan non jiwa baik secara langsung maupun tidak langsung dengan menetapkan sasaran-sasaran yang akan dituju. Sasaran-sasaran tersebut adalah sasaran primer, sekunder, dan tertier. RSJD Dr. RM. Soedjarwadi memanfaatkan media cetak, media luar ruang, media elektronik dan media sosial sesuai dengan karakteristik dan pemanfaatan media dalam hal promosi kesehatan yang ditujukan untuk kegiatan promosi non jiwa dan telah disesuaikan dengan target sasarannya. Metode didaktif yang dilakukan oleh RSJD Dr. RM. Soedjarwadi dengan cara satu arah dapat mendukung tercapainya sasaransasaran yang ingin dituju, seperti sasaran primer, sekunder dan tertier untuk meningkatkan kesadaran kesehatannya.

Teknik komunikasi secara langsung maupun tidak langsung dengan menggunakan media cetak, media elektronik, media luar ruang dan media sosial telah ditentukan oleh RSJD Dr. RM. Soedjarwadi sesuai dengan sasaran yang akan dituju. Karena hal tersebut akan membantu pasien, keluarga pasien, pegawai RSJD dan 
para stakeholders RSJD dalam meningkatkan kesadaran hidup bersih dan sehatnya baik dalam bentuk kegiatan dari promosi kesehatan secara langsung maupun tidak langsung.

RSJD Dr. RM. Soedjarwadi selain menggunakan metode didaktif juga menggunakan metode sokratif dalam melakukan kegiatan promosi kesehatan non jiwa. Metode sokratif dengan menggunakan teknik komunikasi secara langsung dilakukan oleh RSJD Dr. RM. Soedjarwadi yang telah menentukan siapa saja yang akan menjadi sasarannya. Seperti sasaran primer, sekunder dan tertier. dalam teknik komunikasi secara langsung dan tidak langsung dengan menggunakan media massa dirasa telah tepat dalam pemanfaatannya berdasarkan sasaransasaran yang dituju oleh rumah sakit. Dengan menggunakan media cetak, luar ruang, elektronik dan juga sosial akan mampu membantu rumah sakit dalam mepromosikan kesehatan kepada masyarakat. Walaupun ada beberapa kegiatan dari promosi kesehatan yang tidak menggunakan media elektronik dan sosial, karena telah ditentukan berdasarkan sasaran yang ditetapkan oleh rumah sakit.

\section{c.Analisis Strategi Promosi Kesehatan Di RSJD Dr. RM. Soedjarwadi Provinsi Jawa Tengah}

Tujuan promosi kesehatan adalah agar dapat tersosialisasinya program-program kesehatan demi terwujudnya masyarakat Indonesia baru yang dapat berbudaya hidup bersih dan sehat serta diharapkan masyarakat ikut berpartisipasi secara langsung dalam kegiatan promosi kesehatan yang diselenggarakan. Maka, untuk mencapai tujuan tersebut diperlukan sebuat strategi sebelum melakukan kegiatan promosi kesehatan. Strategi merupakan cara yang digunakan guna mencapai apa yang ingin dicapai dalam kegiatan promosi kesehatan. RSJD Dr. RM. Soedjarwadi telah menggunakan strategi-strategi dari komunikasi kesehatan untuk menjalankan kegiatan promosi kesehatan baik untuk jiwa maupun non jiwa. Berikut adalah penjelasan mengenai strategi promosi kesehatan yang digunakan oleh RSJD Dr. RM. Soedjarwadi. 

Kesadaran Hidup Sehat oleh Rumah Sakit Jiwa Daerah Dr. RM. Soedjarwadi Provinsi Jawa Tengah

1) Analisis Strategi Promosi

\section{Kesehatan Jiwa}

Dari ketiga strategi promosi, yaitu advokasi, dukungan sosial dan pemberdayaan masyarakat, kesehatan yang dilakukan untuk kesehatan jiwa belum semuanya tercapai. Dapat dilihat pengelompokkan yang telah dilakukan oleh penulis bahwa tidak semua sasaran (sasaran primer, sekunder dan tertier) termasuk kedalam strategi advokasi, dukungan sosial dan pemberdayaan masyarakat. Sedangkan untuk bentuk dari strategi promosi kesehatan dan media promosi kesehatan sudah cukup dalam mendukung kegiatan promosi kesehatan jiwa. Hal ini karena media-media yang digunakan telah disesuaikan dengan sasaran-sasaran yang akan menjadi penerima atau komunikan dari promosi kesehatan.

\section{2) Analisis Strategi Promosi Kesehatan Non Jiwa}

Ketiga strategi promosi kesehatan, yaitu advokasi, dukungan sosial dan pemberdayaan masyarakat yang dilakukan untuk kesehatan non jiwa sasarannya belum semuanya tercapai. Dapat dilihat dari pengelompokkan yang telah dilakukan oleh penulis, bahwa tidak semua sasaran (sasaran primer, sekunder dan tertier) termasuk ke dalam strategi advokasi, dukungan sosial, dan pemberdayaan masyarakat, sedangkan untuk bentuk dari strategi promosi kesehatan dan media promosi kesehatan sudah cukup dalam mendukung kegiatan promosi kesehatan non jiwa. Hal ini dikarenakan media-media massa yang digunakan oleh RSJD Dr. RM. Soedjarwadi telah disesuaikan dengan sasaran-sasaran yang akan menjadi penerima pesan atau informasi kesehatan.

\section{3) Analisis SWOT Strategi Promosi Kesehatan Jiwa dan Non Jiwa}

Kekuatan (strengths) dan peluang (oppurtunities) metode promosi kesehatan yang ada di RSJD Dr. RM. Soedjarwadi adalah dengan menerapkan metode didaktif dan metode sokratif baik secara langsung maupun tidak langsung dapat membantu sasaran baik primer, sekunder maupun tertier menanamkan kesadaran akan hidup bersih dan sehat didalam dirinya. Dengan menggunakan metode didaktif, akan mempermudah masyarakat dalam mengakses informasi kesehatan karena melalui media massa. Sedangkan untuk metode sokratif adalah dapat melihat apakah semua sasaran baik primer, sekunder maupun tertier menangkap pesan atau informasi kesehatan yang telah disampaikan oleh komunikator sehingga dapat diharapkan sasaran-sasaran tersebut dapat meningkatkan kesadaran akan hidup bersih dan sehat, sedangkan dalam strategi promosi kesehatan advokasi adalah dapat mendukung melalui sarana maupun prasarana dalam bidang kesehatan dan menjalin kemitraan dengan para sasaran tertier baik dalam bidang kesehatan maupun diluar bidang kesehatan. 
Sedangkan untuk strategi dukungan sosial dapat membantu tim IPKRS rumah sakit dalam menyampaikan pesan, informasi ataupun program mengenai kesehatan jiwa dan non jiwa kepada masyarakat dengan melalui bantuan dari para tokoh masyarakat atau yang lainnya. Terakhir strategi pemberdayaan masyarakat dapat meningkatkan dan menanamkan kesadaran akan hidup bersih dan sehat didalam diri para target sasaran primer, sekunder dan tertier.

Kelemaham (weakness) dan ancaman (threats) yang ada pada metode didaktif adalah hanya mengandalkan media massa sebagai media perantara penyampaian pesan kesehatan, sehingga komunikator tidak dapat mengetahui dampak dari kegiatan promosi kesehatan yang dilakukan dengan menggunakan metode didaktif baik secara langsung maupun tidak langsung karena komunikan bersifat pasif. Sedangkan untuk metode sokratif adalah perencanaan sebelum melaksanakan kegiatan promosi kesehatan diperlukan waktu dan tenaga yang relatif banyak dan memerlukan keahlian khusus, sedangkan dalam strategi promosi kesehatan yang dilakukan oleh RSJD Dr. RM. Soedjarwadi adalah strategi advokasi dalam bentuk lobi politik adalah susahnya mendapatkan kepercayaan dari sasaran tertier, sedangkan dalam seminar dan atau presentasi adalah meyakinkan sasaransasaran yang dituju dalam membangun program-program kesehatan untuk nantinya diterapkan dimasyarakat.
Selanjutnya, dalam bentuk media advokasi, semakin berkembangnya zaman dan teknologi maka akan semakin banyak pula inovasi-inovasi yang harus dikeluarkan agar dapat menarik perhatian sasaran. Terakhir, perkumpulan (asosiasi) minat. Kelompok sering kali sulit menerima pendapat atau saran dalam sebuah perkumpulan.

Strategi dukungan sosial dalam bentuk bina suasana individu adalah dalam meyakinkan para masyarakat agar mau untuk menerima atau menerapkan mengenai program-program kesehatan yang disampaikan. Selanjutnya, bina suasana kelompok dimana nantinya kelompok masyarakat sedikit demi sedikit tidak perduli lagi akan kesehatannya karena tidak adanya inovasi terbaru dalam penyampaian informasi kesehatan yang diberikan oleh rumah sakit. Terakhir adalah bina suasana publik, yaitu dengan semakin berkembangnya jaman dan teknologi maka harus lebih kreatif dan inovatif dalam memberikan informasi kesehatan melalui media massa. Sedangkan strategi pemberdayaan masyarakat, yaitu tidak diterapkannya cara hidup bersih dan sehat dalam kehidupan sehari-hari yang diberikan saat melakukan kegiatan-kegiatan seperti misalnya penyuluhan langsung maupun tidak langsung. 

Kesadaran Hidup Sehat oleh Rumah Sakit Jiwa Daerah Dr. RM. Soedjarwadi Provinsi Jawa Tengah

\section{Penutup}

Hasil penelitian ini adalah tim dari PKRS RSJD Dr. RM. Soedjarwadi menggunakan strategi promosi kesehatan untuk menjalankan promosi kesehatan. Strategi promosi kesehatan yang digunakan adalah advokasi. Advokasi lebih ditujukan kepada stakeholders namun masyarakat juga dijadikan sebagai target sasaran. Advokasi untuk stakeholders, RSJD Dr. RM. Soedjarwadi melakukan dalam bentuk lobi politik, yaitu kegiatan yang dilakukan melalui rapat-rapat dengan melibatkan pemangku kepentingan yang diadakan setiap bulan. Selanjutnya seminar dan atau presentasi, dimana RSJD Dr. RM. Soedjarwadi membahas masalah kesehatan didepan pembuat keputusan baik lintas program maupun lintas sektoral. Terakhir, dalam bentuk perkumpulan (asosiasi) minat. RSJD Dr. RM. Soedjarwadi melakukan rapat komite medik dengan para dokter seperti dokterdokter spesialis yang diadakan sebulan sekali setiap tahun.

Strategi promosi kesehatan selanjutnya yang digunakan oleh RSJD Dr. RM. Soedjarwadi dalam melakukan promosi kesehatan adalah dukungan sosial. Dukungan sosial yang dilakukan oleh RSJD Dr. RM. Soedjarwadi adalah dengan melaksanakan bakti sosial didaerah-daerah atau pedesaan yang melibatkan para tokoh masyarakat. Strategi dari dukungan sosial ini disebut dengan bina suasana, RSJD Dr. RM.
Soedjarwadi menggunakan media leaflet dan banner dalam menjalankan promosi kesehatan. Bentuk strategi bina suasana ini dibagi menjadi tiga kategori. Pertama bina suasana individu, PKRS RSJD Dr. RM. Soedjarwadi menjalin hubungan dengan para tokoh masyarakat, TKSK (Tenaga Kesejahteraan Sosial Kecamatan), dan para dokter yang berada dipuskesmaspuskesmas daerah yang dituju dalam penyuluhan kesehatan. Kedua adalah bina suasana kelompok, dimana tim PKRS melakukan bina suasana kelompok dengan kelompok masyarakat yang berada di daerah Klaten, yaitu PWRI dengan melalui penyuluhan ceramah. Ketiga bina suasana publik, RSJD Dr. RM. Soedjarwadi melakukan promosi kesehatan dengan memanfaatkan media komunikasi leaflet, brosur, majalah, x-banner, buku agenda ide, direktori, banner, spanduk, baliho, sticker, papan reklame, TV kabel Sujarwadi, youtube, e-mail, website, instagram, twitter, facebook, fax, undangan, poster, dan bekerjasama dengan radio RSPD Kabupaten Klaten. Strategi promosi kesehatan selanjutnya yang digunakan oleh RSJD Dr. RM. Soedjarwadi adalah pemberdayaan masyarakat. Kegiatan promosi kesehatan dengan menggunakan strategi ini terdiri dari dropping pasien atau pemulangan pasien yang dilaksanakan sebanyak 12 kali dalam setahun. Selanjutnya, penyuluhan kesehatan yang dilaksanakan sebanyak 26 kali dalam satu tahun terdiri dari 16 kali penyuluhan didalam gedung rumah sakit 
dan 10 kali penyuluhan diluar gedung rumah sakit. Kemudian, home visit, home visit dilaksanakan sebanyak 20 kali dalam satu tahun. Kegiatan yang selanjutnya adalah family therapy, family therapy dilaksanakan sebanyak 12 kali dalam satu tahun terdiri dari 8 kali terapi untuk dewasa dan 4 kali terapi untuk anak dan remaja.Selanjutnya temu pelanggan, temu pelanggan dilaksanakan 2 kali dalam satu tahun dengan melibatkan para keluarga pasien. Kemudian seminar kesehatan jiwa sebanyak 2 kali dalam satu tahun dengan komunikator para dokter umum maupun spesialis dan juga psikolog. Terakhir adalah promkesmen atau pameran kesehatan yang dilaksanakan didalam maupun diluar gedung rumah sakit dilaksanakan 1 kali dalam setahun dengan melibatkan hasil karya dari para pasien rehabilitan.

\section{Daftar Pustaka}

\section{Buku}
Ali, Zaidin. 2010. Dasar-Dasar Pendidikan Kesehatan Masyarakat dan Promosi Kesehatan. Jakarta: Trans Info Media.

Arifin, Zainal. 2012. Penelitian Pendidikan Metode dan Paradigma Baru. Bandung: Rosdakarya.

Azwar, Saifuddin. 1998. Metode Penelitian. Yogyakarta: Pustaka Pelajar.

Cangara, Hafied. 2014. Perencanaan \& Strategi Komunikasi (Edisi Revisi). Jakarta: Rajawali Pers.

Depkes RI. 1992. Persyaratan Kesehatan Lingkungan Rumah Sakit, Peraturan Menteri Kesehatan Republik Indonesia No. 986/Menkes/Per/11/1992. Jakarta: Depkes RI.

Depkes RI. 2006. Pedoman Penyelenggaraan dan Prosedur Rekam Medis Rumah Sakit di Indonesia. Jakarta: Depkes RI.
Depkes RI. 2009. Pedoman Pelayanan Antenatal di Tingkat Pelayanan Dasar. Jakarta: Depkes RI.

Djamal, M. 2015. Paradigma Penelitian Kualitatif. Rev.ed. Yogyakarta: Pustaka Pelajar.

Hartono, Bambang. 2010. Promosi Kesehatan Di Puskesmas Dan Rumah Sakit. Jakarta: Rineka Cipta.

Kholid, Ahmad. 2012. Promosi Kesehatan Dengan Pendekatan Teori Perilaku, Media, Dan Aplikasinya. Jakarta: PT. RajaGrafindo Persada.

Kriyantono, Rachmat. 2007. Teknik Praktis Riset Komunikasi: Disertai Contoh Praktis Riset Media, Public Relations, Advertising, Komunikasi Organisasi, Komunikasi Pemasaran. Jakarta: Kencana.

Liliweri, Alo. 2007. Dasar-Dasar Komunikasi Kesehatan. Yogyakarta: Pustaka Pelajar. 
Mubarak dan Chayatin. 2008. Ilmu Kesehatan Masyarakat: Teori dan Aplikasi. Jakarta: Penerbit Salemba Medika.

Mulyana, Deddy. 2010. Ilmu Komunikasi Suatu Pengantar. Bandung: PT. Remaja Rosdakarya.

Moleong, Lexy. J. 2002. Metodologi Penelitian Kualitatif. Bandung: PT. Remaja Rosdakarya.

Nasir, Mohammad. 2003. Metode Penelitian. Jakarta: Ghalia Indonesia.

Notoatmodjo, S. 2005. Promosi Kesehatan: Teori dan Aplikasi. Jakarta: Rineka Cipta.

Nugroho, Rian. 2003. Kebijakan Publik, Formulasi, Implementasi dan Evaluasi. Jakarta: Media Komputindo.

Purenda, Angga. "RSJD Klaten Luncurkan Sujarwadi TV," Radar Klaten, 4 Agustus 2016.

Rakhmat, Jalaludin. 2001. Metode Penelitian Komunikasi. Bandung: PT. Remaja Rosdakarya.

Rakhmat, Jalaludin. 2005. Psikologi Komunikasi. Bandung: PT. Remaja Rosdakarya.

Solang, Sesca Diana, Nansy Losu, dan Naomy Marie Tando. 2016. Promosi Kesehatan Untuk Mahasiswa Kebidanan. Bogor: In Media.

Sugiyono. 2013. Metode Penelitian Kuantitatif, Kualitatif dan $R \& D$. Cet-19. Bandung: Alfabeta, CV.

Sulistyo, Basuki. 2006. Metode Penelitian. Jakarta: Wedatama Widya Sastra dan Fakultas Ilmu Pengetahuan Budaya Universitas Islam Indonesia.

Suprapto, Tommy. 2006. Pengantar Teori Komunikasi. Cetakan Ke-1. Yogyakarta: Media Pressindo.
Wardani, Ika Novita, Yanik Muyassaroh, Murti Ani. 2016. Buku Ajar Promosi Kesehatan Untuk Mahasiswa Kebidanan. Jakarta: Trans Info Media.

Yatim, Riyanto. 1996. Metodelogi Penelitian Pendidikan: Suatu Tinjauan Dasar. Surabaya: SIC.

Zuriah, Nurul. 2006. Metodologi Penelitian Sosial Dan Pendidikan Teori-Aplikasi. Jakarta: Bumi Aksara.

\section{Skripsi/Tesis}

Ilham, T. Muhammad. "Strategi Komunikasi Seksi Promosi Kesehatan Kota Bandung Dalam Mensosialisasikan Bahaya Penyakit AIDS (Studi Deskriptif Strategi Komunikasi Bagian Promosi Kesehatan Dinas Kesehatan Kota Bandung dalam Mensosialisasikan Bahaya Penyakit AIDS pada Remaja melalui Penyuluhan Kesehatan di SMPN 2 Bandung)," Skripsi Sarjana, Fakultas Ilmu Sosial dan Ilmu Politik Universitas Komputer Indonesia, Bandung, 2011.

Sutopo, Faizal Rachman. "Manajemen Program Komunikasi Terapeutik (Studi Deskriptif pada RSJD. Dr. RM. Sodjarwadi Provinsi Jawa Tengah)," Skripsi Sarjana, Fakultas Psikologi dan Ilmu Sosial Budaya Universitas Islam Indonesia, Yogyakarta, 2014.

Wahyono, Hadi. "Promosi Kesehatan Pada Rumah Sakit Swasta, Studi Kualitatif Di Rumah Sakit Bethesda Yogyakarta," Tesis Pasca Sarjana, Fakultas Kedokteran Universitas Gadjah Mada, Yogyakarta, 2013. 
Sari, Dian Andita. "Pengaruh Promosi Kesehatan Tentang Perilaku Hidup Bersih dan Sehat (PHBS) Terhadap Sikap dan Perilaku Hidup Bersih dan Sehat Siswa Kelas III Di Sekolah Dasar Tamansari I Wirobrajan Yogyakarta Tahun 2010," Skripsi Sarjana, Program Studi Ilmu Keperawatan Sekolah Tinggi Ilmu Kesehatan 'Aisyiyah', Yogyakarta, 2016.

\section{Jurnal}

Alhamda, Syukra. "Analisis Kebutuhan Sumber Daya Promosi Kesehatan Di Rumah Sakit Umum Daerah Solok, Sumatera Barat," Jurnal Manajemen Pelayanan Kesehatan. Vol. 15 No. 2 (Juni, 2012), hal 7785 .

Komariah, Kokom. "Pola Komunikasi Kesehatan dalam Pelayanan dan Pemberian Informasi mengenai Penyakit TBC pada Puskesmas di Kabupaten Bogor," Jurnal Kajian Komunikasi. Vol. 1 No. 2 (Desember, 2013), hal 173-185.

Putra, Firman Yulian. "Strategi Promosi Kesehatan Dinas Kesehatan Kabupaten Kutai Kartanegara Tentang Pemahaman Perilaku Hidup Bersih dan Sehat (PHBS) Di Puskesmas Mangkurawang," $e$ Journal Ilmu Komunikasi, 4 (1), 2016: 74-87.

Rahmat, Pupu Saeful. "Penelitian Kualitatif," Jurnal Equilibrium Vol. 5 No. 9 (Januari-Juni, 2009), hal 18.

Rezeki, S., Mulyadi, A., dan Nopriadi. "Strategi Promosi Kesehatan Terhadap Peningkatan Perilaku Hidup Bersih Dan Sehat Individu Pada Masyarakat Perkebunan Di Wilayah Puskemas Sei Kijang Kabupaten Pelalawan," Jurnal Ilmu Lingkungan.
Yusuf, Yusri, Muh. Syafar, dan Burhanuddin Bahar. "Analisis Strategi Promosi Kesehatan Di Puskesmas Bambalamonu Dalam Pembinaan Masyarakat Suku Da'a Di Desa Kasaluang Kab. Mamuju Utara,” Jurnal MKMI, Vol. 6 No. 3 (Juli, 2010), hal. 141-145.

\section{Internet}

Kementerian Kesehatan. (2014). Undang Undang No 18 Tahun 2014 Tentang Kesehatan Jiwa

www.binfar.kemkes.go.id?wpdact $+=$ proce ss\&did=MjAxlmhvdGxpbms

(Diakses 20 Februari 2017).

"Modul Promosi Kesehatan di Masyarakat.”

www.pamsimas.org (Diakses pada 10 Agustus 2017).

“(PDF) Undang Undang No. 44 Th 2009 tentang Rumah Sakit Kementerian Kesehatan”

www.depkes.go.id (Diakses pada 19 Februari 2017).

Website Rumah Sakit Jiwa Daerah Dr. RM. Soedjarwadi Provinsi Jawa Tengah

www.rsjd-

sujarwadi.jatengprov.go.id/ipkrs/2 017/02/14/penyuluhan-kesehatantentang-vertigo/ (Diakses pada 19 Maret 2017).

Website Rumah Sakit Jiwa Daerah Dr. RM. Soedjarwadi Provinsi Jawa Tengah

www.rsjd-sujarwadi.jatengprov.go.id (Diakses pada 20 Maret 2017).

Website Rumah Sakit Jiwa Daerah Dr. RM. Soedjarwadi Provinsi Jawa Tengah

www.rsjd-sujarwadi.com/tentangkami/struktur-organisasi(Diakses pada 20 Maret 2017). 
Ratih Gayatri Setyabudi \& Mutia Dewi, Analisis Strategi Promosi Kesehatan dalam Rangka Meningkatkan Kesadaran Hidup Sehat oleh Rumah Sakit Jiwa Daerah Dr. RM. Soedjarwadi Provinsi Jawa Tengah

Website Rumah Sakit Jiwa Daerah Dr. RM. Soedjarwadi Provinsi Jawa Tengah

www.rsjd-sujarwadi.com/yankes/alurpelayanan (Diakses pada 20 Maret 2017)

WebsiteRumah Sakit Jiwa Daerah Dr. RM. Soedjarwadi Provinsi Jawa Tengah www.rsjd-

sujarwadi.com/yankes/rawatinap(Diakses pada 20 Maret 2017)

Website Rumah Sakit Jiwa Daerah Dr. RM. $\underline{\text { Soedjarwadi Provinsi Jawa Tengah }}$

www.rsjd-sujarwadi.com/kesehatan/hkjs2015-seminar-kesehatan-jiwaoleh-kak-seto (Diakses pada 11 Agustus 2017).

Website Rumah Sakit Jiwa Daerah Dr. RM. Soedjarwadi Provinsi Jawa Tengah

www.rsjd-sujarwadi.com/galeri-karyarehabilitan-soedjarwadi/ (Diakses 11 Agustus 2017).

Facebook Rumah Sakit Jiwa Daerah Dr. RM. Soedjarwadi Provinsi Jawa Tengah

https://free.facebook.com/public/Rsjd-

Soedjarwadi? $\mathrm{rdc}=1 \& \mathrm{rdr}$ (Diakses 30 Juli 2017). 
Jurnal komunikasi, Volume 12, Nomor 1, Oktober 2017 